\title{
Association of gjb2 gene mutations with non syndromic autosomal recessive deafness in different populations of the world
}

\author{
Shahid Hussain*, Mohammad Haroon Khan, Mohammad Tahir Khan, Shuja Zeb, \\ Muhammad Haseeb, Asad Ullah Tariq \\ Department of Bioinformatics Mohammad Ali Jinnah University, Islamabad Expressway, Kahuta Road, Zone-V Islamabad \\ *Corresponding author E-mail: shahid.hussain@jinnah.edu.pk
}

Copyright () 2014 Mr. Shahid Hussain et al. This is an open access article distributed under the Creative Commons Attribution License, which permits unrestricted use, distribution, and reproduction in any medium, provided the original work is properly cited.

\begin{abstract}
Background: More than 90 variants of the GJB2 gene have been reported. Objectives: We analyzed the reported mutation data of hearing loss impairment from different countries through Meta-analysis to evaluate the influence of the mutations in GJB2 gene on the risk of NSHL and the differential distribution in its frequency as described in the previous studies. We were mainly concerned with the inclusion of dubious studies as they could lead to notorious outcomes. Methods: The data was retrieved from online databases with different keywords to include the data from 1997 to 2013. Full length papers were obtained wherever possible. A total of 22 case-control studies were included in the meta-analysis. Results: The analysis was performed for the total included data having 14254 patients and 9721/14254 patient cases with GJB2 mutation along with 3427 controls and 56/3427 mutant controls. Genetic association was measured by using the pooled odd ratios along with $95 \% \mathrm{CI}(\mathrm{OR}=2.72,95 \% \mathrm{CI}$ : 2.48 2.97) by using the random effect model. The forest plot on the association of mutation carriers demonstrated that there was higher mutations prevalence in the case group. Most of the data points were located within 95\%CI which indicates the association of mutation and increased risk of NSHL but showed variation within the regional disparity or ethnic specificity. Conclusions: The Meta-analysis was conducted in different ethnic group, the results showed a strong association of GJB2 mutations with the increased risk of hearing loss in the selected populations.
\end{abstract}

Keywords: Deafness, Conexin 26, GJB2, Meta-Analysis, NSHL.

\section{Introduction}

Deafness is found to be the most common sensory disorder which affects $1 / 1000$ neonates, Environmental and genetic factors are both important for causing hearing loss [1], but the later one is the most likely factor for hearing impairment [2]. Congenital hearing loss is a highly heterogeneous defect, which can be classified into syndromic (30\%) and non-syndromic (70\%) disorders. Non-syndromic is either Autosomal dominant, Autosomal recessive, X-linked or mitochondrial mutations. [3], [4] Autosomal recessive, Autosomal dominant, X-linked are denoted as DFNB, DFNA and DFN respectively [1].

In non syndromic autosomal recessive deafness, a total of 44 genes and 75 loci have been discovered. In autosomal recessive deafness DFNB1 was the first incriminated locus. GJB2 gene (13q11) is responsible for hearing loss at this locus [5]. GJB2 gene has two exons in total but has only one coding exon is $5.5 \mathrm{~Kb}$ in length, while its mRNA is 2.4 $\mathrm{Kb}$ in size. The protein chain synthesized by GJB2 gene has 226 amino acids and is a member of conexin family, a membrane protein and has four Tran's membrane domains [6].

Hearing loss prevalence reveals that conexin 26 is more sensitive to mutations and so is involved in approximately 50\% deafness worldwide. Approximately 60 different types of mutations have been detected in this short region [7]. The previous studies have shown that, most of the discovered cases are found in families having high consanguineous marriages [8]. In the current study, we analyzed the data of mutations found from different past studies of hearing loss impairment from different countries through Meta-analysis, focusing on combing and contrasting their results. 


\section{Material and methods}

\subsection{Search strategy and outcome}

The data was retrieved by searching different online databases including Science direct, Pubmed, Google scholar, Human genetic mutation database, GJB2 Homepage, Hearing loss homepage and Chinese biomedical literature. The more recent studies were selected and year wise frame for selection was kept from 1997 to 2013. The keywords used to search relevant studies were non syndromic hearing loss (NSHL), Conexin 26 (Cx26), GJB2 Mutation and variants. The full text papers were retrieved wherever possible. The selection criteria for research articles were narrow down by keeping few important parameters constant. All relevant articles were found by retrieving related citation, which were not found by direct search.

\subsection{Study selection and data extraction}

A broad search was done to study the maximum available literature from 1997 to 2013 . Only the recently published data providing full information we needed were included in the study. We manually examined the traced articles for inclusion by keeping the following parameters in front, (1) Full information of Author/s (2) Year of publication (3) Country of study (4) Total number of patients selected (5) Number of patient with mutation (6) Total number of control samples (7) Number of control with mutation and (8) Type of mutation detected. Total time given for data retrieving was 30 days and a total of 113 most relevant papers published in peer reviewed journals associated with GJB2 mutations and NSHL susceptibility were extracted, Data was taken for Meta-analysis from 22 studies fulfilling our required criterion as mentioned above. The primary table constructed for analysis is shown in table-1.

Table 1: Study Design and Sample Size of Studies Included in the Meta-Analysis

\begin{tabular}{|c|c|c|c|c|c|c|c|}
\hline S. No & First Author & Country & PWM & Patients & Controls & CWM & MT \\
\hline 1 & Zelante et al. (1997) [9] & Morocco & 28 & 81 & 113 & 3 & 35delG \\
\hline 2 & Green et al.(1999) [10] & Kuwait & 12 & 100 & 85 & 0 & 35delG \\
\hline 3 & Park et al. (2000a) [11] & UK & 9014 & 9139 & 125 & 0 & 35delG \\
\hline 4 & Park et al. (2000b) [11] & Brazil & 37 & 300 & 100 & 0 & 35delG \\
\hline 5 & Abe et al. (2000) [12] & China & 26 & 100 & 109 & 3 & 235delC \\
\hline 6 & Marlin et al. (2001) [13] & USA & 29 & 52 & 560 & 0 & 35delG \\
\hline 7 & RamShankar et al. (2003) [14] & Korea & 68 & 147 & 100 & 23 & V27I \\
\hline 8 & Xiao et al. (2004) [15] & Korea & 38 & 147 & 100 & 5 & E114G \\
\hline 9 & Ramchander et al. (2005) [16] & Italian & 34 & 54 & 50 & 0 & 35delG \\
\hline 10 & Ruszymah et al. (2005) [17] & Mongolia & 14 & 534 & 217 & 2 & 235delC \\
\hline 11 & Abidi et al. (2007) [18] & Egypt & 7 & 78 & 150 & 0 & 59delT \\
\hline 12 & Batissoco et al. (2009) [19] & India & 28 & 303 & 200 & 0 & W24X \\
\hline 13 & Chen et al. (2009) [20] & India & 13 & 200 & 200 & 0 & W24X \\
\hline 14 & Zainal et al. (2009) [21] & India & 36 & 215 & 60 & 5 & W24X \\
\hline 15 & Padma et al. (2009) [22] & Malaysia & 8 & 51 & 100 & 0 & V37I \\
\hline 16 & Tekin et al. (2010) [23] & France & 127 & 169 & 116 & 0 & 35delG \\
\hline 17 & Tsukada et al. (2010) [24] & Japan & 10 & 70 & 96 & 2 & 235delC \\
\hline 18 & Hall et al. (2012) [25] & Malaysia & 7 & 60 & 60 & 6 & G4D \\
\hline 19 & Al-Sebeih et al. (2013) [26] & Japan & 35 & 1511 & 252 & 2 & 235delC \\
\hline 20 & Meguid et al. (2013) [27] & China & 10 & 69 & 100 & 2 & 235delC \\
\hline 21 & Wei et al. (2013) [28] & China & 102 & 658 & 462 & 3 & 235delC \\
\hline 22 & Miyagawa et al. (2013) [29] & Japan & 38 & 216 & 72 & 0 & 235delC \\
\hline
\end{tabular}

PWM=Patients with mutation CWM=Control with mutation MT=Mutation type

\subsection{Data analysis}

A Study attrition diagram was initially constructed for the collected data for Meta-analysis of GJB2 Mutations (Fig-1). A Study Design table was constructed to provide the relevant information selected in our study (table-1). The data was taken as whole exact results from each individual study. The total number of sample cases used and the number of cases with mutation were analyzed. Along with the number of controls used and number of controls with mutation. The Meta analysis was performed for the total included data from 22 studies reported from different countries. By using fixed or random effect model along with $95 \% \mathrm{CI}$, to measure the genetic association, the pooled odd ratio was calculated. I-squared, Cochran's Q and Chi2-p analysis was also performed for OR. The Forest plot showing results regarding total number of patients and controls shown as Fig-2. A funnel plot was also constructed to analyze the data for publication biasness. 


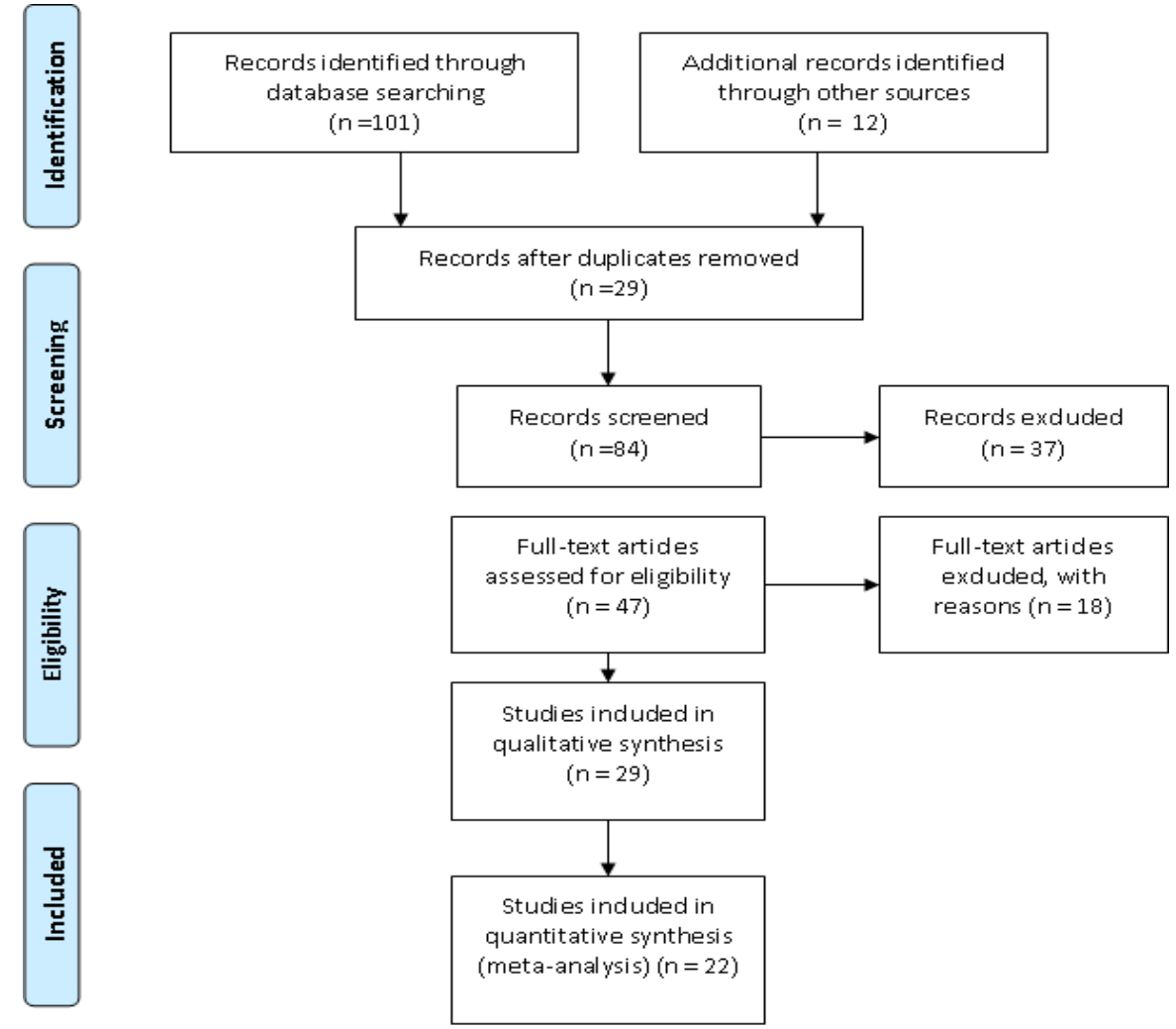

Fig. 1: Study Attrition Diagram for Meta-Analysis of GJB2 Mutations Studies

\section{Results}

The literature search according our set criteria retrieved a total of 113 publications (abstracts/full length papers). There were only 29 papers containing the required information about the mutation carrier frequencies of GJB2 allele (Table1). The mutation of GJB2 gene with full information was detected only in 22 studies. These case-control studies, comprising 14254 total patients of NSHL and total 9721/14254 patient cases with GJB2 mutation. 3427 controls and 56/3427 mutant control were also included in the study along with the cases (Table- 2).

Table 2: Pooled in Odd Ratios, 95\% CI and Cochran Q of the Included Studies.

\begin{tabular}{|c|c|c|c|c|}
\hline First Author & Pooled ln OR & LCI 95\% & HCI 95\% & Cochran Q \\
\hline Zelante et al. (1997) [9] & 2.78 & 2.52 & 3.04 & 132.15 \\
\hline Green et al.(1999) [10] & 2.78 & 2.53 & 3.03 & 132.30 \\
\hline Park et al. (2000a) [11] & 2.43 & 2.16 & 2.70 & 85.70 \\
\hline Park et al. (2000b) [12] & 2.78 & 2.52 & 3.03 & 131.82 \\
\hline Abe et al. (2000) [12] & 2.80 & 2.54 & 3.05 & 133.26 \\
\hline Marlin et al. (2001) [13] & 2.72 & 2.46 & 2.97 & 118.18 \\
\hline RamShankar et al. (2003) [14] & 3.08 & 2.78 & 3.38 & 108.68 \\
\hline Xiao et al. (2004) [15] & 2.84 & 2.58 & 3.10 & 133.13 \\
\hline Ramchander et al. (2005) [16] & 2.75 & 2.49 & 3.00 & 127.35 \\
\hline Ruszymah et al. (2005) [17] & 2.83 & 2.58 & 3.09 & 130.73 \\
\hline Abidi et al. (2007) [18] & 2.78 & 2.53 & 3.03 & 132.08 \\
\hline Batissoco et al. (2009) [19] & 2.77 & 2.52 & 3.02 & 131.04 \\
\hline Chen et al. (2009) [20] & 2.78 & 2.53 & 3.03 & 132.02 \\
\hline Zainal et al. (2009) [21] & 2.91 & 2.64 & 3.17 & 124.25 \\
\hline Padma et al. (2009) [22] & 2.78 & 2.52 & 3.03 & 131.76 \\
\hline Tekin et al. (2010) [23] & 2.65 & 2.40 & 2.91 & 116.47 \\
\hline Tsukada et al. (2010) [24] & 2.80 & 2.54 & 3.06 & 132.93 \\
\hline Hall et al. (2012) [25] & 2.89 & 2.62 & 3.15 & 119.32 \\
\hline $\begin{array}{l}\text { Al-Sebeih et al. (2013) [26 } \\
\text { ] }\end{array}$ & 2.84 & 2.59 & 3.10 & 131.12 \\
\hline Meguid et al. (2013) [27] & 2.80 & 2.54 & 3.06 & 132.97 \\
\hline Wei et al. (2013) [28] & 2.74 & 2.48 & 3.00 & 128.41 \\
\hline Miyagawa et al. (2013) [29] & 2.77 & 2.52 & 3.03 & 131.66 \\
\hline Pooled & 2.79 & 2.53 & 3.038 & 100 \\
\hline \multicolumn{5}{|l|}{ Statistics } \\
\hline I-squared & 84.18 & 77.20 & 89.02 & \\
\hline Cochran's Q & 132.71 & & & \\
\hline
\end{tabular}


Random effect model was used to calculate odd ratio. The forest plot on the association of mutation carriers with the risk of hearing loss was fulfilled $(\mathrm{OR}=2.72$, 95\%CI: $2.48 \sim 2.97$, as shown in Figure 2,

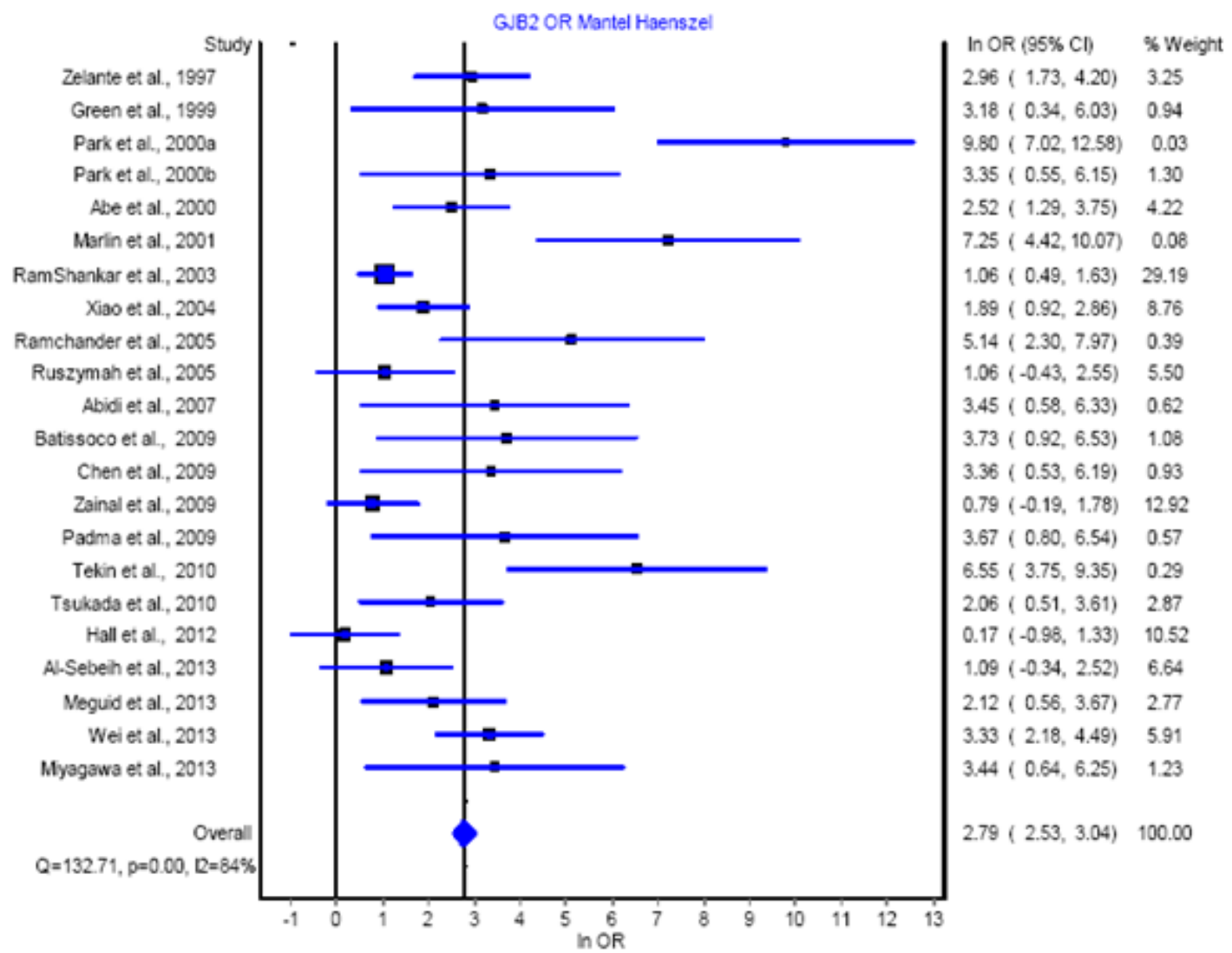

Fig. 2: Forest Plot on the Association of GJB2 Mutations with the Risk of NSHL.

The pooled odd ratio and $95 \%$ CI values confirmed that the case group had a high prevalence of mutations than in the control group. The publication bias was examined by using the funnel plot (Fig-3).

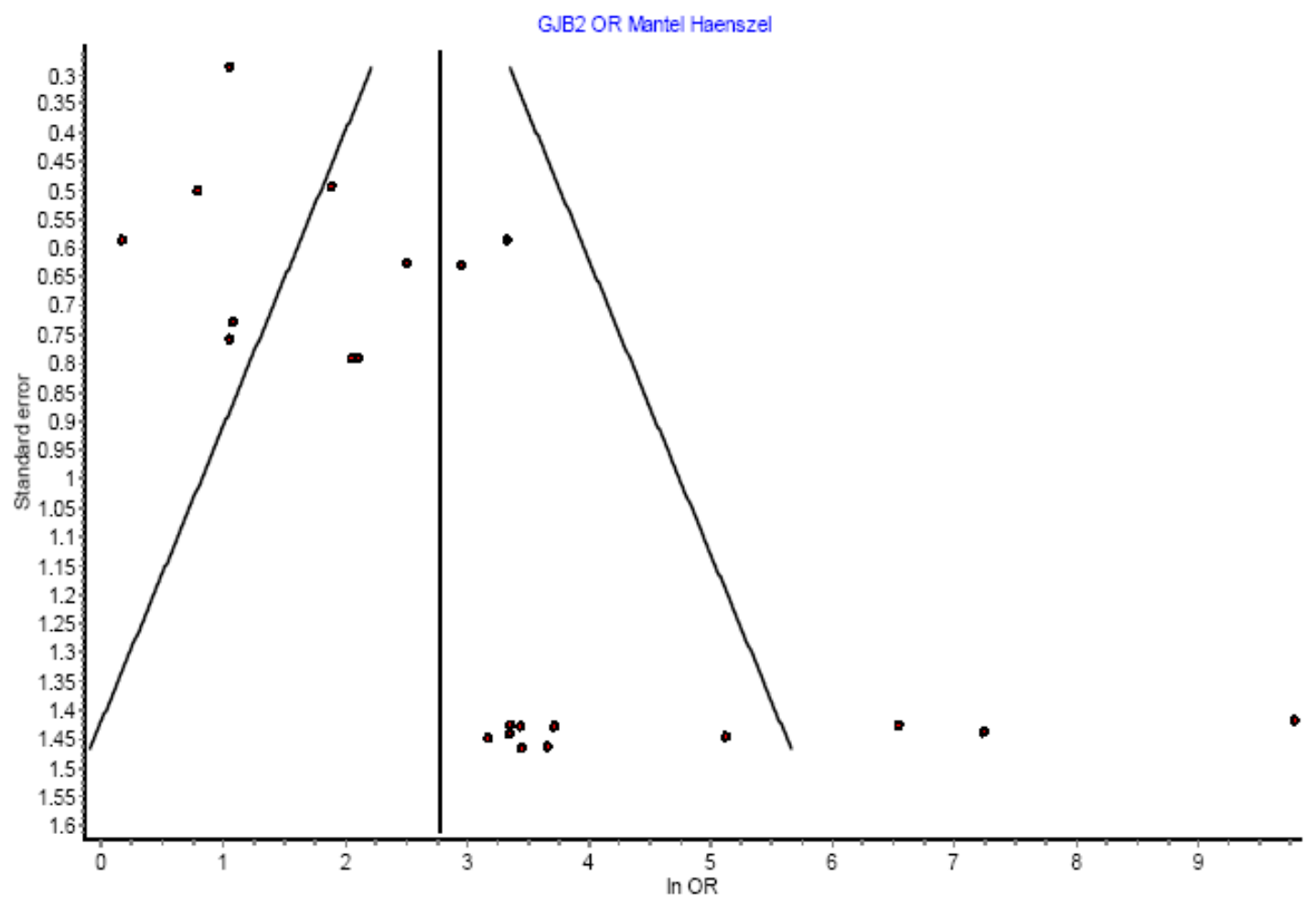

Fig. 3: Funnel Plot Assessing Publication Bias on Combined Effects Comparing the Effect. 
The visual inspection of funnel plot seemed to be symmetrical, and most of the data points were located within $95 \%$ CI. This indicates the association of mutation with the risk of non syndromic hearing loss was varied due to the ethnic specificity or regional disparity. To elucidate the prevalence of mutations related to the NSHL susceptibility more precisely, the stratified Meta-analysis was subsequently performed according to the regional Studies. A total of 22 published papers compromising 9855 patient cases and 3634 controls were included in the stratified Meta-analysis. The pooled odd ratio was calculated using random effect model. Forest plot on the association of mutation carriers with the risk of non syndromic hearing loss was constructed (pooled OR=16.21, pooled 95\% LCI $=12.59$, pooled 95\% $\mathrm{HCI}=20.87)($ Fig-2). The pooled odd ratio and 95\%CI values demonstrated that the mutation of GJB2 gene was significantly associated with the risk of NSHL in all population. The visual inspection of funnel plot was symmetrical (Fig-3), and most of the data points were observed within $95 \% \mathrm{CI}$.

\section{Discussion}

Mutations in GJB2 gene are considered as the major cause of NSHL in many populations worldwide. This review by means of a meta-analysis was focused to evaluate the affect GJB2 gene mutations on NSHL. The investigation on the uniformity in genetic correlation was usually leveled to the genetic effect and genetic model. The genetic effect was focused on the diversity in study prospective, methods, interaction and linkage disequilibrium. [22]. While the genetic model was focused on the difference in association between the disease and heterozygote or homozygote and the risk of the disease. The environmental and genetic factors influence the association/correlation between the susceptibility to NSHL and GJB2 gene mutations. The case control studies with high sample size is evaluated with a potential tool called Meta- analysis, which detect even a small effects of genetic association and between-study heterogeneity. By analyzing the data with Meta-analysis it was determined that, GJB2 mutants have high level of risk for hearing loss but significant genetic-effect heterogeneity and between-study heterogeneity were found, which indicates the importance of regional disparity and ethnic specificity in association between the GJB2 gene mutations of the hearing loss susceptibility. From the result it was observed that the GJB2 mutations were associated with the risk of non syndromic hearing loss in different populations. Our extracted data indicates diversity in genetic affects based on the extracted studies. It also shows that GJB2 Gene trended to be consistent with recessive model in all studied population, which implies that other populations may have other multiple models. Due to a complex heterogeneity and interaction between environmental factors and genetic mutations this field needs to be evaluated further more to study the prevalence of the mutations in GJB2 gene related to the none syndromic hearing loss susceptibility with different ethnic specificity and regional disparity.

To evaluate the susceptibility of GJB2 mutation in NSHL a Meta-analysis was performed for many studies conducted in different ethnic groups. By pooling all relevant studies the results of Meta-analysis showed a strong association of GJB2 mutations with hearing loss. However genetic effect due to heterogeneity of NSHL was not shown due to ethnic specificity and regional disparity. Therefore Meta-analysis was conducted in different ethnic group and the results declared that GJB2 mutations were significantly associated with the risk of hearing loss in the selected populations.

\section{References}

[1] N.E. Morton. Genetic epidemiology of hearing impairment, Ann NY Acad Sci 630 (1991) 16-31. http://dx.doi.org/10.1111/j.17496632.1991.tb19572.x.

[2] M.L. Marazita, L.M.Ploughman, B.Rawlings. Genetic epidemiological studies of early- onset deafness in the US school-age population. Am J Med Genet 46 (1993) 486-491. http://dx.doi.org/10.1002/ajmg.1320460504.

[3] M.B. Petersena, P.J. Willemsb. Non-syndromic, autosomalrecessive deafness, Clin Genet 69 (2006) $371-392$. http://dx.doi.org/10.1111/j.1399-0004.2006.00613.x.

[4] M. Mukherjee, S.R. Phadke, B. Mittal. Connexin 26 and autosomal recessive non-syndromic hearing loss, Indian J. Hum Genet 9 (2003) 4050 .

[5] D.P. Kelsell, J. Dunlop, H.P.Stevens. Connexin 26 mutations in hereditary non-syndromic sensorineural deafness, Nature 387 (1997) $80-83$. http://dx.doi.org/10.1038/387080a0.

[6] P.M. Kelley, D.J. Harris, B.C. Novel mutations in the connexin 26 gene (GJB2) that cause autosomal recessive (DFNB1) hearing loss. Am J Hum Genet 62 (1998) 792-799. http://dx.doi.org/10.1086/301807.

[7] P. Gasparini, R. Rabionet, G. Barbujani. High carrier frequency of the 35delG deafness mutation in European populations. Genetic Analysis Consortium of GJB2 35delG, Eur J Hum Genet 8 (2000) 19-23. http://dx.doi.org/10.1038/sj.ejhg.5200406.

[8] W.E. Nance, X.Z. Liu, A. Pandya. Relation between choice of partner and high frequency of connexin-26 deafness, Lancet 356 (2000) 500501. http://dx.doi.org/10.1016/S0140-6736 (00)02565-4.

[9] L. Zelante, P. Gasparini, X. Estivill X. Connexin26 mutations associated with the most common form of non-syndromic neurosensory autosomal recessive deafness (DFNB1) in Mediterraneans. Hum Mol Genet 6 (1997) 1605-1609. http://dx.doi.org/10.1093/hmg/6.9.1605

[10] G.E. Green, D.A. Scott, J.M. McDonald. Carrier rates in the midwestern United States for GJB2 mutations causing inherited deafness, JAMA (16) 1999 2211-2216.

[11] H.J. Park, S. Hahn, Y. Chun. Connexin26 mutations associated with nonsyndromic hearing loss. Laryngoscope110 (2000) $1535-1538$. http://dx.doi.org/10.1097/00005537-200009000-00023.

[12] S. Abe, S. Usami, H. Shinkawa H. Prevalent connexin 26 gene (GJB2) mutations in Japanese, J Med Genet 37 (2000) $41-43$. http://dx.doi.org/10.1136/jmg.37.1.41 
[13] S. Marlin, E.N. Garabedian,G. Roger. Connexin 26 gene mutations in congenitally deaf children: pitfalls for genetic counseling, Arch Otolaryngol Head Neck Surg 127 (2001) 927-933. http://dx.doi.org/10.1001/archotol.127.8.927.

[14] M. RamShankar, S. Girirajan, O. Dagan. Contribution of connexin26 (GJB2) mutations and founder effect to non-syndromic hearing loss in India, J. Med. Genet 40 (2003) 68. http://dx.doi.org/10.1136/jmg.40.5.e68.

[15] Z.Z. Xiao, D.H. Xie DH. GJB2 (Cx26) gene mutations in Chinese patients with congenital sensorineural deafness and a report of one novel mutation, CMJ 117 (2004) 1797-1801.

[16] P.V. Ramchander, V.U. Nandur, K. Dwarakanath. Prevalence of Cx26 (GJB2) gene muta- tions causing recessive nonsyndromic hearing impairment in India, Int. J. Hum Genet 5 (2005) 241-246.

[17] B.H. Ruszymah, I.F. Wahida, Y. Zakinah, Z. Zahari, M.D. Norazlinda, L. Saim, B.S. Aminuddin. Congenital deafness: high prevalence of a V37I mutation in the GJB2 gene among deaf school children in Alor Setar, Med J Malaysia 60 (2005) 269-74.

[18] O. Abidi, B. Redouane, N. Halima N. GJB2 (connexin 26) gene mutations in Moroccan patients with autosomal recessive non-syndromic hearing loss and carrier frequency of the common GJB2-35delG mutation, Int. J. Pediatr. Otorhinolaryngol 71 (2007) 1239-1245. http://dx.doi.org/10.1016/j.ijporl.2007.04.019.

[19] A.C. Batissoco, R.S Abreu-Silva, M.C Braga MC. Prevalence of GJB2 (connexin-26) and GJB6 (connexin-30) mutations in a cohort of 300 Brazilian hearing-impaired individuals: implications for diagnosis and genetic counseling, Ear Hear 30 (2009)1-7. http://hereditaryhearingloss.org/main.aspx?c=.HHH\&n=86316 dated: 02/12/2013.

[20] D. Chen, X. Chen, K. Cao. High prevalence of the connexin26 (GJB2) mutation in Chinese cochlear implant recipients, ORL J Otorhinolaryngol Relat Spec 71 (2009) 212-215. http://dx.doi.org/10.1159/000229300.

[21] S.A. Zainal, M.K.H. Md-Daud, A.R. Normastura. DHPLC analysis of GJB2 gene among malays with non-syndromic hearing loss: preliminary results, Proceedings of the 8th Malaysia Congress on Genetics, 4-6 August 2009, Genting Highlands, Malaysia

[22] G. Padma, P.V.Ramchander, U.V.Nandur. GJB2 and GJB6 gene mutations found in Indian probands with congenital hearing impairment, J. Genet 88 (2009) 267-272. http://dx.doi.org/10.1007/s12041-009-0039-5.

[23] M. Tekin, X.J. Xia, R. Erdenetungalag, F.B. Cengiz. GJB2 mutations in Mongolia: complex alleles, low frequency, and reduced fitness of the deaf, Ann Hum Genet 74 (2010)155 164. http://dx.doi.org/10.1111/j.1469-1809.2010.00564.x.

[24] K. Tsukada, S. Nishio, S. Usami. The Deafness Gene Study Consortium. A large cohort study of GJB2 mutations in Japanese hearing loss patients, Clin Genet 78 (2010) 464-470. http://dx.doi.org/10.1111/j.1399-0004.2010.01407.x.

[25] A. Hall, P. Marcus, L. Mark. Prevalence and audiological features in carriers of GJB2 mutations, c.35delG and c.101T>C (p.M34T), in a UK population study, BMJ Open 2012; 0:e001238/.

[26] K. Al-Sebeih , M. Al-Kandari ,S.A Al-Awadi. Connexin 26 Gene Mutations in Non- Syndromic Hearing Loss among Kuwaiti Patients, Med Princ Pract 23 (2014) 74-79. http://dx.doi.org/10.1159/000348304.

[27] N.A. Meguid NA, Omran MH, Dardir AA, et al. Study of 35delG in congenital sensorineural non-syndromic hearing loss in Egypt, J Appl Sci Res 4 (2008) 621-626.

[28] Q. Wei, S.Wang, J.Yao. Genetic mutations of GJB2 and mitochondrial 12S rRNA in non syndromic hearing loss in Jiangsu Province of China, J Transl Med 11 (2013) 163. http://dx.doi.org/10.1186/1479-5876-11-163.

[29] M. Miyagawa, S.Y. Nishio, S. Usami. Prevalence and clinical features of hearing loss patients with CDH23 mutations: large cohort study, PLoS One 7 (2012) e40366. http://dx.doi.org/10.1371/journal.pone.0040366. 